\section{$\mathrm{Y}-12$}

\section{OAK RIDGE Y-12 PLANT}

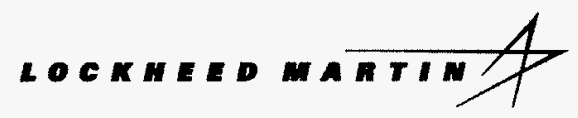

MANAGED BY LOCKHEED MARTIN ENERGY SYSTEMS, INC. FOR THE UNITED STATES DEPARTMENT OF ENERGY
MP? 301898

YIAMT-429

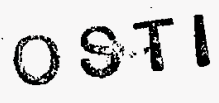

Project Accomplishment Summary for

Project Number 92-Y12P-039-B2

\title{
RAPID RESPONSE MANUFACTURING (RRM)
}

William D. Cain

Lockheed Martin Energy Systems, Inc.

William L. Waddell

National Centers for Manufacturing Sciences (NCMS)

February 18, 1997

Approved for Public Release; distribution is unlimited.

Prepared by the Oak Ridge Y-12 Plant managed by

LOCKHEED MARTIN ENERGY SYSTEMS, INC. for the U.S. DEPARTMENT OF ENERGY under contract DE-AC05-84OR21400

1. TIMBUTION OF THI DOCUMIAT IS UNLINITED

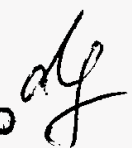




\section{DISCLAIMER}

This report was prepared as an account of work sponsored by an agency of the United States Government. Neither the United States Government nor any agency there of, nor any of their employees, makes any warranty, express or implied, or assumes any legal liability or responsibility for the accuracy, completeness, or usefulness of any information, apparatus, product, or process disclosed, or represents that its use would not infringe privately owned rights. Reference herein to any specific commercial product, process, or service by trade name, trademark, manufacturer, or otherwise, does not necessarily constitute or imply its endorsement, recommendation, or favoring by the United States Government or any agency thereof. The views and opinions of authors expressed herein do not necessarily state or reflect those of the United States Government or any agency thereof. 


\title{
PROJECT ACCOMPLISHMENT SUMMARY
}

\author{
Title: \\ DOE TTI Number: \\ Rapid Response Manufacturing (RRM) \\ CRADA Number: \\ 92-Y12P-039-B2 \\ Partner: \\ PES001-0077 \\ National Centers for Manufacturing Sciences (NCMS)
}

\section{BACKGROUND}

U.S. industry is fighting to maintain its competitive edge in the global market place. Today markets fluctuate rapidly. Companies, to survive, have to be able to respond with quick-to-market, improved, high quality, cost efficient products. The way product is developed and brought to market can be improved and made more efficient through the proper incorporation of emerging technologies. A major technological thrust is needed to develop methods, which permit the effective application, incorporation and use of advanced technologies to facilitate the product realization process.

The U.S. defense complex faces similar challenges in meeting the demands of deploying, supporting, maintaining and extending the life of increasingly complex weapons systems in an austere budget environment. The Defense Programs (DP) arm of the U. S. Department of Energy (DOE), in particular, faces an unprecedented challenge in maintaining its capability to remanufacture and support fielded weapons and produce essential components in a no new production environment where the loss of vital expertise through attrition and downsizing are exacerbated by reductions in budgets and aging of facilities.

The U. S. leads the world in technology research and development but U. S. Industry has not been able to effectively incorporate these technological innovations into their product development environments. The entire development and deployment cycle for product realization needs to be streamlined to make it more efficient and cost effective. Some of the support technology needed to transition to a data-driven parallel-processing environment where product and process information is readily available, sharable, and accessible in a computer interpretable form is not fully developed or commercially available. The RRM project was established to leverage the expertise and resources of U.S. private industries and federal agencies to develop, integrate, and deploy new technologies that meet critical needs for effective product realization. The RRM program addressed a needed change in the U. S. Manufacturing infrastructure that will ensure U. S. competitiveness in world market typified by mass customization.

\section{DESCRIPTION}

Lockheed Martin Energy Systems worked with a NCMS managed consortium of major industrial firms- Ford Motor Company, General Motors, Texas Instruments, United Technologies, and Kodak - and several small suppliers of advanced manufacturing technology - MacNeal-Schwendler Corp., Teknowledge Corp., Cimplex Corp., Concentra, and Spatial Technology Ford Motor Company, General Motors, Texas Instruments and United Technologies - to develop, expound and incorporate key technologies into workable computer-integrated manufacturing environments.

This project provided the effort needed to define, develop and establish a customizable infrastructure for rapid response product development design and manufacturing. A major project achievement was the development of a broad-based framework for automating and integrating the 
product and process design and manufacturing activities involved with machined parts. This was accomplished by coordinating and extending the application of feature-based product modeling, knowledge-based systems, integrated data management, and direct manufacturing technologies in a cooperative integrated computing environment. Key technological advancements include a product model that integrates product and process data in a consistent, minimally redundant manner, an advanced computer-aided engineering environment, "knowledge-based" software aids for design and process planning, and new production technologies to make products directly from design application software.

\section{BENEFITS TO DOE}

The DOE Defense Programs (DP) Office is charged with maintaining the capability for directed nuclear weapons work with fewer people and less resources. This can be achieved through a streamlined design and manufacturing cycle that captures and integrates the knowledge of the complex. The Rapid Response Manufacturing project has developed a broad-based framework for automating and integrating the design and manufacturing activities involved with the production of mechanical products including weapon components. Each RRM industrial partner was able to customize this generic framework, support it with commercial off-the-shelf application software and existing/emerging national and international standards and demonstrate order-of-magnitude time-to-market, cost reduction, and quality improvement for selected part families.

The RRM integrated framework was first demonstrated "live" on a simple prismatic part at the RRM central test bed in October 1994 at the Ford Alpha Center in Dearborn, Michigan. In this live demonstration, the result of an electronic change request was a modification to a feature on a base part which mates in an assembly with a feature on another part. The geometry of a key slot on the base part was modified and changes were sent to a remote site at General Motors to determine the effect and changes needed to the mating key feature on another part. At the same time the new base part model was sent electronically to the Y-12 Plant. At Oak Ridge, new NC machining tool paths and $\mathrm{CMM}$ inspection programs were generated semi-automatically. The NC tool paths were postprocessed, simulated, verified and electronically sent to Ford Alpha manufacturing facility where the part was manufactured. There were audio and visual links to each of the sites that were used for real time collaboration. It took less than $11 / 2$ hours to complete the whole process and proved Y-12's ability to interface electronically within a geographically dispersed environment.

For DOE DP applications, the RRM framework was demonstrated in an environment for automating the design and manufacture of certain classes of turned, milled and drilled parts. The RRM integrated framework has been enhanced for a turned part environment that allows for the automatic generation of $\mathrm{NC}$ machining tools paths for a single family or class of turned parts and the fixtures that hold them. To do this, Y-12 supplied to the Partner the necessary "rules" for the production of this part family and the Partner generated a near turnkey system which automates the generation of NC machining tool paths. This has been demonstrated through simulation inside the Y-12 plant without machining actual parts. The system is such that a single part family of real parts could now be machined using this integrated system once DOE software quality assurance requirements are met. There are plans to continue to develop this system under the $\mathrm{ADaPT}$ program and put it into the NWC weapon parts production stream. This extension involves using real solid models of parts received electronically in their native $\mathrm{CAD}$ format from the design laboratory to drive knowledge-based applications for automatically generating $\mathrm{NC}$ machining 
tools paths and CMM inspection probe paths which in turn can be used to meet testing requirement for software quality assurance.

The RRM project developed and demonstrated some of the "soft" enabling technologies needed by the weapons community in the migration path from the traditional serial-processing methods of today to the data-driven parallel-processing environment of tomorrow where product data is readily available, sharable and accessible in a computer interpretable form. Some of the key technologies include a manufacturing model that integrates product and process data in a consistent manner, an advanced computer-aided engineering environment, "knowledge-based" software aids for design and process planning and new production technologies to make products directly from design software. This "soft" technology may be use to streamline and automate existing DOE NWC production cycles.

\section{ECONOMIC IMPACT}

Each of the major industrial participants, Ford, GM, United Technologies and Texas Instruments, was able to demonstrate an implementation of a customized RRM framework in a production environment. In every case, significant improvements in time-to-market, development and production costs, and quality were achieved. All of the companies have plans to expand their implementations of the RRM framework and soft technologies to other product lines. Y-12 has begun to develop production quality integrated application support software for DP use. Y-12 should to be able to product high quality products cheaper and faster using less people and resources using technology developed within the RRM project.

\section{PROJECT STATUS}

The RRM project concluded October 1, 1996.

\section{CONTACTS}

Lockheed Martin Energy Systems, Inc.

W. D. Cain

Y-12 Production Laboratory

P. O. Box 2009, MS 8201, Bldg. 9111

Oak Ridge, TN 37831

Phone: 423-547-3235

Fax: $\quad 423-574-5458$

National Centers for Manufacturing Sciences

William L. Waddell

3025 Boardwalk

Ann Arbor, MI 48108-3266

Phone: $313-995-4903$

Fax: $\quad 313-995-1150$

\section{PROJECT EXAMPLE}

Traditionally, attempts to develop and deploy large integrated manufacturing systems have ended in failure. The infrastructure developed for these large systems has virtually guaranteed that they would be costly, slow, unwieldy, inadequate, inflexible, and, in most cases, outdated before completion. These systems have not had the desired effect of being able to rapidly design and 
produce inexpensive, high quality parts. The Rapid Response Manufacturing (RRM) project is trying to rectify this by defining and deploying an infrastructure which readily supports the building and evolution of customized production-ready manufacturing systems composed of proprietary and commercial-off-the-shelf products. This involves developing a highly flexible infrastructure, which is:

- extensible,

- easily modified, and

- open.

RRM task groups have been formed to define and develop the various components of the RRM infrastructure. Figure 1 shows how these groups should work together and interact to produce RRM requirements and specifications. The major components of the RRM infrastructure that are initially being addressed are:

- reference architecture,

- database management system,

- interfaces to support seamless integration,

- interoperable applications, and

- advanced RRM applications.

In order to insure that each group's work fits within the context of the RRM infrastructure, a dynamic flexible testbed for rapid deployment, testing and validation needs to establish. A testbed should be implemented immediately. Early testing and validation is needed to keep the program from developing requirements and specifications which are not realistic, implementable, or capable of producing the desired results

\section{TECHNOLOGY COMMERCIALIZATION}

Several software products developed from requirements within the RRM project are now commercially available. The following is a list of the companies and the products they have developed and now market which resulted from the RRM endeavor.

Concentra:

- ICAD/Parametric Technology ICAD/RASNA, ICAD/SDRC and ICAD/STEP AP 203 Integration Toolkits

- Parametric Sketcher

-. Glass Box Utility

MacNeal Schwendler

- Analysis Advisor

- Materials Characterization Database

- PATRAN/STEP AP 203 Interface

Unigraphics

- Tolerance and Physical Interface Analysis (Next Version) 


\section{DISTRIBUTION}

William Cain, MS-8201, 9111

Ray Ford, MS-8084, 9203

Andy Stevens, DOE OR, MS-8009, 9704-2

Diane Bird, DOE DP-17

Bill Wilburn, MS-8015, 9704-2

Y-12 Central Files, MS 8169, 9711-5 (3 copies)

William L. Waddell, NCMS, 3025 Boardwalk, Ann Arbor, MI 48108-3266 (5 copies) 
Report Number (14)_Y/A1UT- - 129

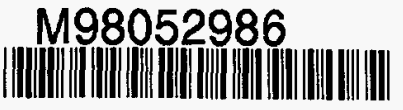

Publ. Date (11)

Sponsor Code (18)

UC Category (19)

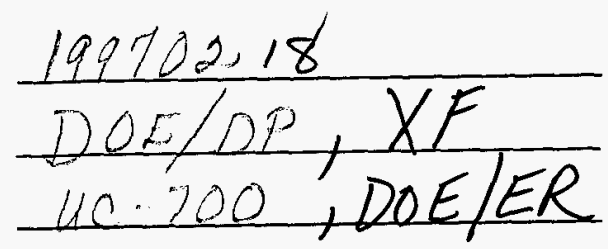

19980707087

DTIO QUALTTY DNBPECTER 1

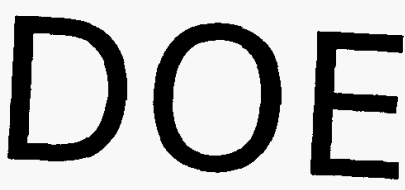

